\title{
Critical Factors for Implementing and Diffusing Sustainable Product-Service Systems: Insights from Innovation Studies and Companies' Experiences
}

\author{
Fabrizio Ceschin
}

Brunel University London, College of Engineering, Design and Physical Sciences, Department of Design, Uxbridge, UB8 3PH, United Kingdom

$$
T+44 \text { (0) } 1895267394
$$

fabrizio.ceschin@brunel.ac.uk

\section{Pre-print version of the paper published in the Journal of Cleaner Production:}

Ceschin F. (2013) Critical factors for implementing and diffusing sustainable product-Service systems: insights from innovation studies and companies' experiences. Journal of Cleaner Production 45: 74-88. 


\section{Abstract}

Eco-efficient Product-Service System (PSS) innovations represent a promising approach to sustainability. However the adoption of such business strategies is still very limited because it often involves significant corporate, cultural and regulatory barriers. An important challenge is not only to conceive eco-efficient PSS concepts, but also to understand the contextual conditions that facilitate their societal embedding, and which strategies and development pathways are the most appropriate.

The combination of theoretical insights from innovation studies (in particular Strategic Niche Management and Transition Management) and a case studies research (exploring the innovation journeys made by six companies in introducing their eco-efficient PSS innovations in the market) is used to investigate the factors that influence the implementation and diffusion of this kind of innovations. The article provides a structured overview of these factors, grouping them in four clusters: implementation of socio-technical experiments; establishment of a broad network of actors; building up of a shared project vision; creation of room for broad and reflexive learning processes.

Based on these results it is argued that a broader and more strategic system approach should be adopted by companies. Companies should focus not only on the PSS solution and its value chain, but also on the contextual conditions that may favour or hinder the societal embedding of the PSS itself. The article concludes by outlining a key area for future research.

Keywords: Product-Service System (PSS); Sustainability; Commercialisation; Strategic Niche Management; Transition Management; Socio-technical experiments.

\section{Introduction}

Conditions for sustainability require a system discontinuity, meaning that a radical redefinition of current structures of production and consumption is needed (Factor 10 Club 1994; Vergragt and van Grootveld 1994; Schmidt-Bleek 1996; WBCSD 1996). Given the dimension of the required change it is therefore clear that innovations on a process and product level, although being fundamental and necessary, are not alone sufficient to obtain the just mentioned radical shift. For these reasons, if we want to effectively tackle sustainability, there is a need to move from a focus on product improvements only, towards a wider systemic approach that takes in consideration new potential ways of satisfying the social demand of wellbeing. In this perspective, as suggested by Stahel $(1986,1989)$, it is considered promising to move from an industrial economy, in which the central value is based on the exchange of products to be consumed and in which the growth is strongly linked to resources consumption, to a functional economy, in which products are mere means of providing functions (or better still satisfactions). A functional economy is oriented to satisfy consumers through the delivery 
of functions (e.g. mobility; thermal comfort; having clean clothes) instead of products (e.g. cars; boilers and methane; washing machines and powder).

Within this perspective several authors refer to the concept of Product-Service System (PSS) innovation as a promising business model (Goedkoop et al. 1999; UNEP 2002; Mont 2004; Tukker and Tischner 2006a; Baines et al. 2007). A PSS can be described as an integrated system of products, services and socio-economical stakeholders, designed to fulfil a specific client need (Goedkoop et al. 1999), with the word system referring to both the system of products and services delivered to the customer, and the system of actors that produce and deliver the combination of products and services. It is a "total offer", including products and services, such as insurance, guarantees, maintenance and product upgrading, repair, takeback and refurbishing (Williams 2007). PSS is not a new economic concept: several examples of PSS have in fact been implemented in the last decades by various companies (Goedkoop et al. 1999; UNEP 2002; Mont 2004; Vezzoli 2007). However, the key point to be underlined is that a PSS, if properly conceived, can potentially decouple economic value from material and energy consumption ${ }^{1}$ (Mont 2002; Manzini and Vezzoli 2003; Tukker and Tischner 2006c). These PSSs are defined eco-efficient (UNEP 2002; Vezzoli 2007): PSS in which the economic and competitive interests (of the socio-economical stakeholders involved in the PSS offer) continuously foster improvements in resource productivity (e.g. if the material artefact remains in the ownership of the producer then there is an economic incentive to design and deliver long lasting products in order to postpone maintenance and disposal costs and the costs for manufacturing of new products (Halme et al. 2004)).

A wide number of research projects in the field of PSS and sustainability have been recently supported by EU funding ${ }^{2}$, and several methods and tools have been developed in the last years to orient and support the designing of eco-efficient PSSs ${ }^{3}$. However, despite all the knowledge accumulated, it has to be underlined that the application of this concept is still very limited. The reason is that eco-efficient PSSs are in most of the cases ${ }^{4}$ radical innovations, because they challenge existing customers' habits (cultural barriers), companies' organizations (corporate barriers) and regulative frameworks (regulative barriers) (UNEP 2002; Mont 2002; Tukker and Tischner 2006a).

Schot and Geels (2008) consider radical innovations always immature when they enter the mainstream market because they cope with a dominant socio-technical context (and its

\footnotetext{
${ }^{1}$ It has to be underlined that not all PSS are sustainable (Mont 2004; Tukker \& Tischner 2006c; Cook et al. 2006). They have a potential to contribute to sustainability only if carefully designed.

${ }^{2}$ For instance: PROSECCO - Product \& Service Co-Design process (2002-2004, FP5); HiCS - Highly Costumerized Solutions (2001-2004, FP5); MEPSS - Method for PSS development (2001-2004, FP5); SusProNet - the sustainable product-service design network (2002-2004, FP5); SCORE! - Sustainable COncumption Research Exchange! (20062009, FP6).

${ }^{3}$ See for example DES, Design of eco-efficient services methodology (Brezet et al. 2001); PSS innovation scan for industry (Tukker \& van Halen 2003); HiCS, Highly Customerised Solutions (Manzini, Collina and Evans, 2004); MEPSS, Methodology for Product Service System development (van Halen, Vezzoli \& Wimmer 2005); Practical guide for PSS development (Tukker \& Tischner 2006b); MSDS, Method for System Design for Sustainability (Vezzoli, Ceschin \& Cortesi 2009; Vezzoli 2010).

${ }^{4}$ We are in particular referring to sustainable PSS in the B2C market, while in the B2B sector numerous examples of sustainable PSS concepts can be identified.
} 
established and stable rules and networks of actors). Eco-efficient PSS innovations are in most of the cases such a radical innovation. In fact, as underlined by Tukker and Tischner (2006c), eco-efficient PSS implementation cannot be realised by simply asking a company to change its business model alone, because changes in the socio-technical context are most of times also required. Hence, for those companies that do see eco-efficient PSS as key to their future, an important challenge is not only to conceive eco-efficient PSS concepts, but also to understand the contextual conditions in which they are introduced and which strategies and development pathways are the most appropriate.

Although the concept of eco-efficient PSS has been discussed in the literature for over a decade, not much attention has been devoted to understand how the process of introduction and diffusion takes place, and how it can be managed and oriented (Tukker and Tischner 2006c; Baines et Al. 2007). This paper intends to be a contribution to fill this gap. In particular the paper aims to identify the critical factors which contribute to the successful implementation of eco-efficient PSSs.

In order to determine these factors we propose to build upon the field of innovation studies. Recent developments in the research streams that focus on system innovations and socio-technical transitions (i.e. Strategic Niche Management and Transition Management approaches), have provided insights on how to facilitate the introduction and diffusion of radical innovations. According to these theories, the introduction of these innovations requires the creation of partially protected socio-technical experiments in which various actors exchange knowledge, information and experience (Schot and Hoogma 1996; Kemp et al. 1998, 2001; Loorbach 2002). These experiments represent strategic opportunities to incubate radical innovations and help to overcome the innovation inertia derived from the established cultural, organisational and regulatory rules. For these experimentations to be successful, it is emphasised the importance of involving a broad network of social actors, aligning and converging their expectations, and creating room for broad and reflexive learning processes (Raven 2005).

In seeking to deepen understanding of the potential contribution that SNM and TM could make in addressing the problems underlined above, this paper begins by illustrating the barriers which hinder the implementation and diffusion of eco-efficient PSSs, and discussing which insights from SNM and TM are relevant for the specificities of this kind of innovations. Building upon this discussion the paper presents a conceptual framework for the implementation and diffusion of eco-efficient PSSs. The framework provides a structured overview of the factors considered important to increase the chances for a successful societal embedding process. A case studies analysis, investigating the innovation journeys made by six companies in introducing their eco-efficient PSS concepts in the market, is then used to validate and refine the framework. The methodology adopted for the case studies, and the related results are illustrated and discussed in the third section. Based on the case studies results, the article concludes by outlining a key area for future research. 


\section{Eco-efficient PSS implementation and diffusion: contributions from innovation studies?}

\subsection{Eco-efficient PSS implementation and diffusion barriers}

Despite all the knowledge accumulated on understanding how to develop eco-efficient PSSs, and despite their potential win-win characteristics, the diffusion of this concept is still very limited. The reason is that eco-efficient PSSs are intrinsically radical innovations, and the adoption of such business strategies brings with significant corporate, cultural and regulatory challenges.

For companies the adoption of an eco-efficient PSS strategy is more complex to be managed than the traditional way of delivering products alone. In fact there is the need to implement changes in corporate culture and organisation in order to support a more systemic innovation and service-oriented business (UNEP 2002), and the need to cope with an internal resistance to extend the involvement with a product beyond point-of-sale (Stoughton et al. 1998). Moreover, since PSSs determine the changing of systems and sources of gaining profit, this could deter producers from employing this concept (Mont 2002): PSSs in fact require medium-long term investments and are connected with uncertainties about cash flows (Mont 2004). A further obstacle is the difficulty of quantifying the savings arising from PSS in economic and environmental terms, in order to market the innovation to stakeholders both inside and outside the company, or to the company's strategic partners (UNEP 2002). In synthesis companies require, as a consequence, new design and management knowledge and skills.

For customers, the main barrier is the cultural shift necessary to value an ownerless way of having a satisfaction fulfilled, as opposed to owning a product (Goedkoop et al. 1999; Manzini et al. 2001; Mont 2002; UNEP 2002). In fact, as argued by Behrendt et al. (2003), the problem is that solutions based on sharing and access contradict the dominant and well established norm of ownership ${ }^{5}$, and requires new customers habits and behaviours. It has also to be underlined that product ownership not only provides function to private users, but also status, image and a sense of control (James and Hopkinson 2002); elements which are sometimes missing in ownerless based solutions. Another obstacle is the lack of knowledge about life cycle costs (White et al. 1999), which makes it difficult for a user to understand the economic advantages of ownerless based solutions.

On the regulatory side, environmental innovation is often not rewarded at the company level due to lack of internalization of environmental impacts (Mont and Lindhqvist 2003). In addition governments face difficulties in implementing appropriate policies to create corporate

${ }^{5}$ This is especially true in the B2C market, while in the B2B sector numerous examples of eco-efficient PSS concepts can be identified (Stahel, 1997). 
drivers to facilitate the promotion and diffusion of this kind of innovations (Mont and Lindhqvist 2003; Ceschin and Vezzoli 2010).

In synthesis eco-efficient PSS innovations usually encounter the opposition of the existing socio-technical context, because in most of the cases they require a change in the routine behaviours that are daily reproduced by individuals, groups, business communities, governmental institutions, and society at large (Tukker and Tischner 2006c). As a result ecoefficient PSS innovations are often immature when they enter the market and therefore have high probability not to survive under the mainstream selection environment. Since the diffusion of eco-efficient PSSs requires changes in contextual factors conditions, a much broader system approach is therefore needed to facilitate the societal embedding of this kind of radical innovations.

\subsection{Insights from innovation studies}

The challenge of understanding radical innovations has been addressed by innovation studies. Recent developments in this field (in particular the Strategic Niche Management and Transition Management approaches) have focussed on socio-technical transitions and have brought insights on how to facilitate the introduction and diffusion of radical innovations.

Transition theorists refer to system or radical innovations as major changes in the ways societal functions (such as transportation, communication, housing and feeding) are fulfilled (Rip and Kemp 1998; Geels 2002). The dynamics of transitions depend on the interactions between three different functional levels (Geels 2002; 2005): the socio-technical regime (meso level) which refers to the dominant and relatively stable set of culture, practices and institutions related to a specific field (e.g. mobility, energy, etc.); the niche (micro level), a protected space "isolated" from the influence of the dominant regime, where radical innovations can be tested, become more mature, and potentially challenge and change regime practices and institutions; and the landscape (macro level), which represents the social, economic and political context in which actors interact and regimes and niches evolve. Transitions take place through the fruitful coupling of developments at all three levels (Rip and Kemp 1998; Geels and Kemp 2000; Geels 2002): when the regime is sufficiently open to accept radical innovations; when there is enough pressure from the landscape; and when radical innovations developed in niches can exploit the opportunities for change.

Strategic Niche Management (SNM) and Transition Management (TM) are two approaches that share the ambition to stimulate and orient transitions towards sustainability. SNM is an approach which suggests that the introduction and diffusion of radical innovations can be facilitated by the creation of partially protected spaces (niches) for socio-technical experimentation (Kemp et al. 1998; 2001; Hoogma 2000; Hoogma et al. 2002). TM is a broader governance approach aimed at influencing, orienting and facilitating transition processes towards sustainable outcomes (Loorbach 2002; Kemp and Loorbach 2003; Loorbach 2007); it includes a portfolio of systemic instruments, structured in four activity clusters 
(Loorbach 2002; Rotmans 2003; Loorbach and Rotmans 2006): (i) problem structuring, establishment of the transition arena and envisioning; (ii) developing coalitions and transition agendas; (iii) executing projects and experiments; (iv) monitoring, evaluating and learning.

\subsubsection{Socio-technical experiments}

A core element of both SNM and TM is the setting up of a protected environment to conduct socio-technical experiments with innovations that deviate from the regime. Protection from market competition takes place for example through investment grants, tax exemptions, strategic investment by companies, etc., providing an alternative selection environment. Within this protected space continuous experimentations can lead the innovation to mature (Schot and Hoogma 1996). Niches can therefore be used as strategic opportunities for experimenting, learning, improve the innovation and establish new social networks in order to gain momentum for diffusion and challenge dominant regime practices (Kemp et al 1998). Sequences of experiments can gradually help to scale up the new socio-technical practices and institutions from the local level to a global niche level (Raven 2005, Geels and Raven 2006). The movement to a market niche level leads to more exposure to the selection pressure (gradually dismantling of financial protection) but also to more stable shared practices and institutions (reinforcing of socio-institutional protection) (Schot and Geels 2008).

The implementation of local experiments, to test the technical, social, political and economic configuration of the innovation, and favour its societal embedding, could represent a potentially promising strategy for companies who want to shift towards a PSS oriented approach. It has however to be underlined that in this case the concept of experiment should be seen in a different perspective. Firstly, the entry point is not a technological innovation (like it often happens in $\mathrm{SNM}^{6}$ ), but an eco-efficient PSS concept. An eco-efficient PSS concept can of course include some technological artefacts, but the innovative element is mainly related to the social dimension; in fact rather than a new technological artefact, an eco-efficient PSS can be seen as a new form of social organisation. Secondly, the focus is not on many different solutions and innovations at the same time (as it happens in TM (Loorbach 2007)) but on a single eco-efficient PSS innovation. In other words the aim is not to simultaneously focus on different potential ways of meeting a societal challenge, but on a specific eco-efficient PSS innovation (which of course can anyhow evolve during the innovation journey). Thirdly, while for SNM and TM the typical central actor is the policy maker, in this paper experiments (and the whole societal embedding processes) are seen from a company perspective. This means that socio-technical experiments are seen here as a potential strategic tool for companies to facilitate the implementation and diffusion of eco-efficient PSSs.

For these experimentations to be successful, it is emphasised the importance of (i) involving a broad network of social actors, (ii) aligning and converging their expectations, and

\footnotetext{
${ }^{6}$ There are however few exceptions. For example Witkamp et al. (2011) adopted and adapted SNM for the analysis of social entrepreneurship cases.
} 
(iii) creating room for reflexive learning processes (Elzen et al. 1996; Kemp et al. 1998; Raven 2005). Let us analyse these three processes and their implications in relation to eco-efficient PSS innovations.

\subsubsection{Actor network}

The establishment and development of a proper socio-economic network is recognised a crucial process to protect, support and foster radical innovations. This network should be broad, including not only the actors more directly linked with the innovation (such as firms, partners, users, etc.) but also other relevant actors from the science, policy and societal domains (e.g. research centres, governmental institutions, NGOs, special interest groups, etc.) (Raven 2005). In other words it should be a heterogeneous network characterized by scientific, social, economic, politic and cultural linkages. The network should be managed dynamically because different stages of a societal embedding process require different network compositions (Weber et al. 1999).

Van de Poel (2000) argues that outsiders (with respect to the dominant regime) are needed in a network, because they do not share the current regime institutions and practices and therefore they may contribute in the development of innovations that deviate from that regime. In particular he suggests the involvement of three groups of outsiders: outsiders firms (because they can mobilise knowledge and financial and managerial resources to develop such alternative innovations), scientists (because they can introduce new designs, criteria, approaches and concepts), and societal pressure groups (because they have the potential to mobilise insiders in the regime).

Weber et al (1999) also state that insiders should be involved and in particular that government support and protection can be of crucial importance: in the start-up phase in order to give experiments legitimacy and stability; and in the subsequent phases, in order to create widespread support for scaling up the new practices and institutions related to those experiments.

In relation to the scaling up process, van den Bosch et al (2008) also point out that key stakeholders to be involved are actors that have the power and willingness to directly influence the dominant culture, practices and institutions (such as Ministries, policy makers and politicians, etc.), and actors that (in)directly may influence the regime because they have an interest in embedding new sustainable practices in society (such as NGOs, frontrunners in a sector or policy domain, etc.).

In eco-efficient PSSs, a key element is the network of stakeholders that produce and deliver the solution to customers. Therefore, for companies that want to adopt a PSS-oriented approach, network building is a crucial activity. However, what SNM and TM suggest, is to focus not only on the actors directly linked to the PSS solution (partners, suppliers, customers, etc.) but also to the actors that could provide support and protection to that solution. A broader system approach should therefore be adopted by companies, in order to think to the 
contextual conditions that may favour the societal embedding of the PSS innovation, and to what actors could be involved to support this process. It has however to be underlined that this activity could be potentially hindered by the company need to not disclose key information about the PSS innovation.

\subsubsection{Long term vision}

The process of experimenting and embedding radical innovations in the society requires the involvement of many actors from different domains. These actors may hold different expectations about a particular innovation. Therefore it becomes fundamental to manage the diversity of expectations, and their negotiation and alignment (Raven et al. 2008). The convergence of actors' expectations is important in order to give strategic orientation and legitimacy to the innovation development (Kemp et al. 1998; Raven 2005) but also to attract new actors and resources (Raven 2005).

TM suggests that the creation of a shared long term vision can contribute to articulating expectations, formulating agendas and action plans, and coordinating the strategies of the actors involved (Kemp and Rotmans 2004). In fact, as underlined by De Laat (1996), Akrich (1992), Berkhout (2006) and Quist et al. (2006), future scenarios and visions are crucial in order to enrol actors and orient their actions.

It has however to be underlined that expectations are not fixed (Van Lente 1993; Hoogma 2000; Raven 2005): actors can change their views and expectations, as result of the negotiation processes with other actors, but also in reaction to changes in the external environment. As a consequence the long term vision is continuously subjected to refinement and re-orientation.

TM uses broad visions on how to tackle societal challenges, and these visions usually include different potential solutions to target those challenges (Kemp and Rotmans 2004). The development of project visions, to be used as guides to formulate strategies and persuade potential partners and stakeholders, is a common activity done within companies (Marzec 2007). However it has to be remarked that these visions, differently from the TM perspective, usually provide a specific direction to innovations (not broad but rather focussed visions). In relation to eco-efficient PSS innovations, the vision usually consists in a PSS idea or concept (Vezzoli 2007), which includes the general characteristics of the new business model, a sketch of the journey to achieve that vision, the motivations to develop it, and its potential benefits (ibid.). These visions are mainly used to communicate the PSS concept inside the company (e.g. to different departments) or outside (e.g. to project partners, customers, etc.). If a broader network of actors is involved in the process (as TM and SNM suggest), the vision should be built in order to take in consideration also their perspectives and the roles they could play.

\subsubsection{Learning processes}


Learning takes place when individuals assimilate new information and apply it to their subsequent actions (Hall 1993). It is therefore crucial in the process of inducing changes towards the adoption and diffusion of radical innovations, in which new basic belief, behaviours and rules are required (Van de Kerkhof and Wieczorek 2005). An adequate learning process is considered key important in SNM and TM, because it enables adjustments of the innovation and increases chances for a successful diffusion (Raven et al. 2010).

Firstly, an effective learning process should be broad (Weber et al. 1999; Raven 2005; Kemp and van den Bosch 2006), focusing on many dimensions of the problem: not only the technical and economic aspects of the innovation, but also the cultural (societal beliefs, values and habits), regulative (government policy and regulatory frameworks), and institutional (rules and norms) ones.

Secondly, learning should be reflexive (Hoogma and Schot 2001; Raven 2005; Kemp and van den Bosch 2006), implying that both first and second order learning occur. First order learning can result in a correction or resolution of a certain problem (e.g. technical issues). Second order learning (Hall 1993) leads to a paradigm shift, which refers to a change in the problem definition, basic assumptions, norms, values and interpretive frames which govern the decision-making process of individuals, communities and organizations.

In order to stimulate second order learning, several authors (Hoogma and Schot 2001; Lynn et al. 1996; Leonard 1998; Raven 2005; Kemp and van den Bosch 2006) point out the importance of involving a heterogeneous set of different actors in the network.

The implementation of field tests and pilot projects, in order to learn about the technical and usability aspects of a solution, is a common strategy adopted by companies to test their innovations (Lynn et al. 1996). However, what SNM and TM suggest, is to learn on many different dimensions. The challenge for companies is therefore to broaden learning processes in order to include also the cultural, regulative and institutional dimensions. In relation to ecoefficient PSSs, this means that socio-technical experiments should be also used by companies to learn about the different contextual factors that could influence the innovation (e.g. learn about policy measures to promote the PSS, learn about the different barriers that could hinder the implementation of the innovation). The second challenge for companies is to induce learning (in particular second order learning) in other socio-economic actors (e.g. stimulate users in changing their habits, stimulate administrations in implementing appropriate policy measures, etc.). This means that companies should strategically try to influence context conditions in order to favour the adoption and diffusion of their PSS innovations.

\subsection{Conceptual framework}

Building upon the insights from SNM and TM (and their adaptation to the specific characteristics of eco-efficient PSS innovations), a conceptual framework is developed ${ }^{7}$. It

\footnotetext{
7 The conceptual framework is represented using a visualisation that describes a general transition process. However it must be stressed out that this process is seen from the perspective of a company and not from the policy maker one
} 
provides a comprehensive description on how eco-efficient PSS innovations take place and hypothesises the critical factors that have an influence on the process (see fig. 1). In synthesis, the entry point of an eco-efficient PSS innovation is a project vision (I): a PSS idea or concept developed to overcome a societal/business challenge. This project vision provides a direction to the societal embedding process (II), in which a broad network of actors (III) experiments and learns how the project vision can be met. The societal embedding process is based on the implementation of small scale socio-technical experiments, the development and empowerment of a niche, and the scaling up of the PSS innovation (and its related new set of culture, practices and institutions) in the regime. The process is characterised by dynamic adaptation: what is learned by actors leads to a continuous and mutual adjustment of the transition path, the project vision and the actor network itself (IV).

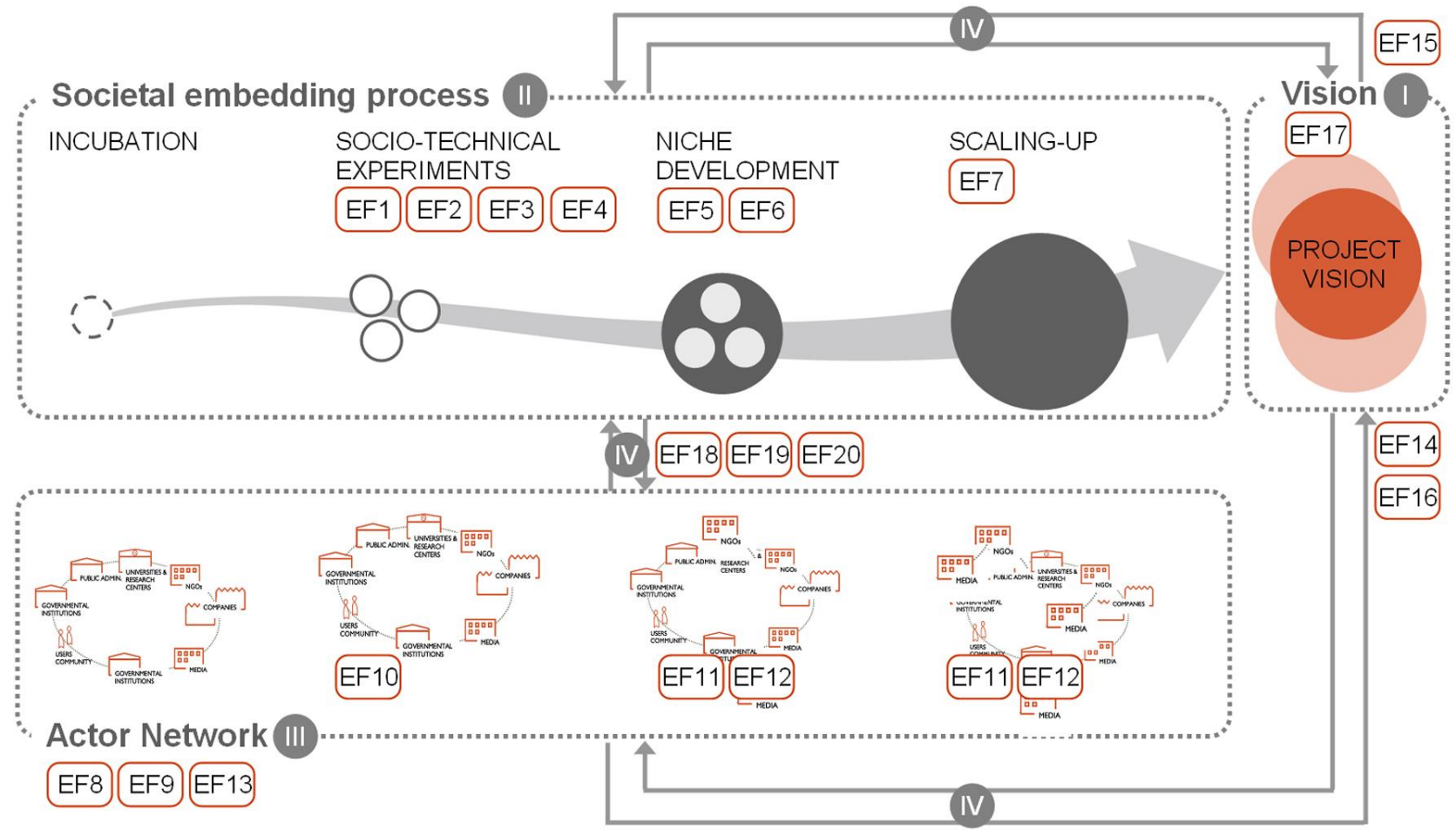

Fig. 1. Conceptual framework for the implementation and diffusion of eco-efficient PSSs. Numbers indicate the expected factors that can influence the process (see table 1).

The project vision consists in an eco-efficient PSS idea or concept, and represents the final goal to be achieved by the company. It provides a direction to the societal embedding process and therefore a direction to the stakeholders' actions. The project vision is key important in enabling the strategic conversation among actors (facilitating therefore the convergence of their expectations), as well as in enrolling new actors in the project.

The societal embedding process is characterized by four main phases:

(as it usually happens in SNM and TM). Thus, insights from SNM and TM were discussed and adapted to fit this perspective. In particular this was done in relation to eco-efficient PSS innovations. 
- incubation, in which the conditions needed to start the process are set up (identification and involvement of needed actors; discussion and negotiation to achieve a common consensus on the PSS concept as well as on the potential strategies to socially embed the concept).

- socio-technical experimentation, in which experiments take place with the aim of learning and exploring how to improve the PSS innovation and contribute to its societal embedding.

- niche development, in which the new set of culture, practices and institutions (related to the PSS innovations) increases its stability and its influence on the regime.

- scaling-up, in which the initially unusual PSS innovation increasingly becomes part of the dominant way in which a societal satisfaction is fulfilled.

The actor network includes all relevant types of actors capable to protect, support and foster the PSS innovation in the different transition phases. Its composition, as well as the required tasks to each actor, continuously evolves in time.

The following table resumes the expected critical factors that can influence the process of societal embedding of eco-efficient PSS innovations. They are grouped in four clusters (societal embedding process, actor network, project vision, learning process) and positioned in fig. 1.

\begin{tabular}{|c|c|c|c|}
\hline & & Expected factors (in successful projects it is expected that...) & Source \\
\hline \multirow{7}{*}{ 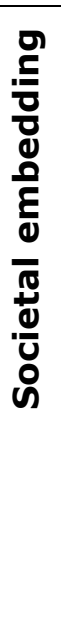 } & 1 & One or more socio-technical experiments are implemented & \\
\hline & 2 & $\begin{array}{l}\text { Socio-technical experiments contribute to learn on many different } \\
\text { dimensions (e.g. technical, user acceptance, political, regulative, cultural } \\
\text { and social acceptance, etc.) }\end{array}$ & $\begin{array}{l}\text { Kemp et al. 1998; } \\
\text { 2001; Hoogma 2000; } \\
\text { Hoogma et al. } 2002\end{array}$ \\
\hline & 3 & $\begin{array}{l}\text { Socio-technical experiments contribute to influence the socio-technical } \\
\text { context in order to stimulate the societal embedding of the PSS innovation }\end{array}$ & $\begin{array}{l}\text { Kemp et al. 1998; } \\
\text { 2001; Hoogma 2000; } \\
\text { Hoogma et al. } 2002\end{array}$ \\
\hline & 4 & $\begin{array}{l}\text { Socio-technical experiments are initially implemented in an environment } \\
\text { protected from the mainstream market selection (financial protection) }\end{array}$ & $\begin{array}{l}\text { Kemp et al. 1998; } \\
\text { Weber et al. } 1999 ; \\
\text { Hoogma et al. } 2002\end{array}$ \\
\hline & 5 & $\begin{array}{l}\text { Niche development is supported by repeating the experiment in a variety of } \\
\text { contexts, and linking the experiment/s to other functions or domains }\end{array}$ & $\begin{array}{l}\text { Geels and Raven } \\
\text { 2006; Rotmans and } \\
\text { Loorbach } 2006\end{array}$ \\
\hline & 6 & $\begin{array}{l}\text { Financial protection of socio-technical experiments is gradually dismantled } \\
\text { during the niche development process, while institutional protection is } \\
\text { reinforced and transferred into mainstream settings }\end{array}$ & $\begin{array}{l}\text { Schot and Geels } \\
2008\end{array}$ \\
\hline & 7 & $\begin{array}{l}\text { Niche development and scaling-up are favoured if there is an alignment of } \\
\text { the niche with events and developments in the landscape }\end{array}$ & Geels 2005 \\
\hline \multirow{6}{*}{ 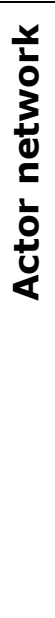 } & 8 & $\begin{array}{l}\text { The stakeholder network is broad (partners, suppliers, users, but also policy } \\
\text { makers, governmental agencies, NGOs, research centres, media etc.) }\end{array}$ & $\begin{array}{l}\text { Hoogma and Schot } \\
2001 ; \text { Raven 2005; } \\
\text { Kemp and van den } \\
\text { Bosch } 2006\end{array}$ \\
\hline & 9 & $\begin{array}{l}\text { The stakeholder network includes both insiders and outsider actors (with } \\
\text { respect to the dominant regime) }\end{array}$ & $\begin{array}{l}\text { Van de Poel } 2000 ; \\
\text { Van den bosh and } \\
\text { Rotmans } 2008\end{array}$ \\
\hline & 10 & $\begin{array}{l}\text { Support and protection from governmental and public institutions could } \\
\text { provide legitimacy and stability to the project }\end{array}$ & Weber et al. 1999 \\
\hline & 11 & $\begin{array}{l}\text { The involvement of actors that have the power and willingness to directly } \\
\text { influence the dominant culture, practices and structure (such as Ministries, } \\
\text { agencies that develop protocols and standards, policy makers, politicians, } \\
\text { directors, etc.) contributes to niche development and scaling-up }\end{array}$ & $\begin{array}{l}\text { Van den bosh and } \\
\text { Rotmans } 2008\end{array}$ \\
\hline & 12 & $\begin{array}{l}\text { The involvement of actors that indirectly influence the regime because they } \\
\text { have an interest in embedding sustainable practices in society (such as } \\
\text { NGOs, sustainability ambassadors, frontrunners in a sector or policy } \\
\text { domain, etc.) contributes to niche development and scaling-up }\end{array}$ & $\begin{array}{l}\text { Van den bosh and } \\
\text { Rotmans } 2008\end{array}$ \\
\hline & 13 & The network composition is kept open to adjustment & Weber et al. 1999 \\
\hline
\end{tabular}




\begin{tabular}{|c|c|c|c|}
\hline \multirow{4}{*}{ 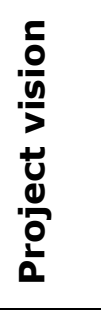 } & 14 & Actors expectations are aligned on a shared project vision & $\begin{array}{l}\text { Kemp and Rotmans } \\
2004\end{array}$ \\
\hline & 15 & $\begin{array}{l}\text { The involvement of different actors in the development of the project vision } \\
\text { (participatory approach) can contribute to build-up a shared vision }\end{array}$ & $\begin{array}{l}\text { Kemp et al. 1998; } \\
\text { Kemp and Rotmans } \\
\text { 2004; Raven } 2005\end{array}$ \\
\hline & 16 & $\begin{array}{l}\text { The development of a clear and robust project vision contributes to attract } \\
\text { resources as well as new actors }\end{array}$ & Raven, 2005 \\
\hline & 17 & The project vision is kept open to adjustments & $\begin{array}{l}\text { Van Lente 1993; } \\
\text { Hoogma } 2000\end{array}$ \\
\hline \multirow{3}{*}{ 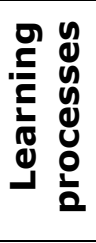 } & 18 & $\begin{array}{l}\text { Learning is broad: learning about the different dimensions of the innovation } \\
\text { (e.g. institutional, technological, socio-cultural, environmental, economical) }\end{array}$ & Raven 2005 \\
\hline & 19 & $\begin{array}{l}\text { Learning is reflexive: there is attention for questioning underlying } \\
\text { assumptions such as social values, and the willingness to change course if } \\
\text { the innovation does not match these assumptions }\end{array}$ & Raven 2005 \\
\hline & 20 & $\begin{array}{l}\text { Reflexive learning is facilitated by the involvement of an heterogeneous set } \\
\text { of different actors in the network }\end{array}$ & $\begin{array}{l}\text { Hoogma and Schot } \\
2001\end{array}$ \\
\hline
\end{tabular}

Table 1. List of the expected critical factors that can influence the process of societal embedding of eco-efficient PSS innovations. Expected factors are grouped in four main clusters. For each expectation it is reported the main source from which the expectation is drawn.

\section{Case studies: methodology and results}

In order to validate and refine the previously presented conceptual framework, a case studies analysis was undertaken. The following text firstly describes the methodology adopted, and then discusses the findings.

\subsection{Methodology}

The case studies analysis was structured in six steps (adaptation from Yin (1989)):

1. Conceptual framework development: a first version of a conceptual framework was developed to provide a description of how eco-efficient PSS innovations take place and which factors influence that process. It represented the theory against which the cases were tested.

2. Cases selection: cases are related to the innovation journeys made by six companies in introducing their eco-efficient PSS innovations ${ }^{8}$ in the market. In particular two contrasting groups of cases can be identified: successful and unsuccessful ones. In this paper a case is considered successful if the result of the innovation journey is (at least) the setting up of market niche in which the innovation is commercialised. This selection strategy (cases that produce contrasting results but for predictable reasons (Yin 1998)) was aimed at verifying how the hypothesised critical factors (identified in the

\footnotetext{
8 The PSS innovations selected are user-oriented PSS (when provider owns the products and made them available to users in different modalities: e.g. leasing, sharing, pooling) and result-oriented PSS (when provider and customer agree on a specific final result; companies offer a customized mix of services and maintain ownership of the products). Product-oriented PSS (when products are still sold, but with some additional services: e.g. maintenance, repair, upgrading, substitution and product take back) have not been included in this study because they usually cannot be considered radical innovations and therefore they can be implemented using consolidated management strategies.
} 
conceptual framework) influence the implementation and diffusion process of ecoefficient PSSs. Moreover, in order to obtain a broader picture of the phenomenon and facilitate the generalisability of results, heterogeneous cases were selected; in fact selected PSS innovations differ in terms of business sector and companies size. Table 2 provides a brief description of each case.

3. Data collection methods selection: in order to enhance the validation of the collected data, the case studies relied on triangulation (Yin 1994): multiple methods for collecting data were used to verify that all sources converged on the facts of a case. Within this research the sources of information are constituted by primary research data and/or secondary sources. Primary sources of data include questionnaires and semi-structured interviews with relevant companies' personnel (e.g. CEOs, directors, project managers, etc.). Secondary sources include companies' internal documents, scientific papers, and case studies made by other researchers.

4. Data Analysis and cases description: collected data were analysed, selected and reduced, and used for the cases descriptions. A deductive approach was coupled with an inductive one. Firstly, the conceptual framework was used to examine if the factors identified in literature found a correspondence in the single cases (deductive reasoning). Secondly, the data collected from each case were used to hypothesise new relevant factors that were not identified in the literature analysis (inductive reasoning).

5. Cross case analysis: After describing the single cases and examining the interrelationship among the factors within each case, a comparison across the cases was undertaken. The aim was to verify if the identified factors were confirmed or rejected, and identify similarities and patterns among cases.

6. Conceptual framework validation and refinement: The results of the cross case analysis were used to validate and refine the conceptual framework built upon the literature review.

\begin{tabular}{|l|l|l|}
\hline Eco-efficient PSS innovation & $\begin{array}{l}\text { PSS } \\
\text { typology }\end{array}$ & $\begin{array}{l}\text { Succes } \\
\text { sful } \\
\text { case }\end{array}$ \\
\hline $\begin{array}{l}\text { CLEAR CHANNEL OUTDOOR, SmartBike, USA } \\
\text { Description of the PSS. SmartBike is a bike sharing system through which users can rent } \\
\text { specifically designed bikes on a per minute basis. SmartBike is thought to be an alternative } \\
\text { and integrative mean of transport, to be used for short trips supplemented by local public } \\
\text { transport vehicles. About the organisation of the system, usually the local municipality } \\
\text { (sometimes together with the local public transport company) covers the initial costs: the } \\
\begin{array}{l}\text { ones related to produce bikes and bike stations. Clear Channel Outdoor manages the service } \\
\text { (and the related costs and revenues). } \\
\text { Brief description of the implementation and diffusion process. The solution was ideated }\end{array}\end{array}$ & Yes \\
\hline
\end{tabular}

\footnotetext{
${ }^{9}$ Primary sources: semi-structured interview with Sergio Verrecchia, project manager of BikeMI (SmartBike service in the city of Milan). Secondary sources: Internal documents provided by Sergio Verrecchia; newspaper articles; websites (www.smartbike.com, www.clearchanneloutdoor.com, www.bikemi.com).
} 


\begin{tabular}{|c|c|c|}
\hline $\begin{array}{l}\text { in } 1997 . \text { Initially the concept was proposed to several municipalities. After some rejections, in } \\
1998 \text { the concept was implemented as a small pilot project in the city of Rennes (France). } \\
\text { This pilot was key important because gave the opportunity to test and improve the innovation } \\
\text { (both from a technical and user acceptance point of view), and also to involve new actors } \\
\text { (synergies were established with the local public transport company), and attract the interest } \\
\text { of new users and other municipalities. In } 1998 \text { the system was scaled up in a full operational } \\
\text { service and from } 2001 \text { replicated in } 15 \text { cities around the world. }\end{array}$ & & \\
\hline $\begin{array}{l}\text { EGO, Ecologico Guardaroba Organizzato, Italy } \\
\text { Description of the PSS. EGO is a system for the shared use of dresses among a limited } \\
\text { number of women. User, after the subscription, selects } 14 \text { clothes (from a sample book) to be } \\
\text { inserted in the "shared wardrobe" (currently the "shared wardrobe" includes } 120 \text { models, } \\
\text { grouped in } 8 \text { different styles). Once a week user selects and picks up } 7 \text { dresses, and at the } \\
\text { same time brings back the dresses used during the previous week. User pays an annual } \\
\text { registration fee plus a monthly subscription. EGO takes care of washing and maintenance. } \\
\text { EGO not only manages the service but also designs the dresses and manages the } \\
\text { manufacturing (outsourced to other Italian companies). } \\
\text { Brief description of the implementation and diffusion process. The PSS concept was } \\
\text { ideated in } 2003 \text { by Vittoria Bono. From } 2003 \text { to } 2008 \text { the business idea was proposed, without } \\
\text { having success, to several financial institutions to get funds. Without external financial } \\
\text { support the concept was firstly implemented in } 2008 \text { as a small pilot project in the city of } \\
\text { Brescia. This pilot was key strategic because gave the opportunity to learn about user } \\
\text { preferences and improve the PSS offer. Thanks to the positive results obtained (and the } \\
\text { support given by local environmental association and media), in } 2009 \text { a new and bigger point } \\
\text { of sale was opened in Milan. In } 2010 \text { a franchising scheme was launched. }\end{array}$ & $\begin{array}{l}\text { B2C } \\
\text { (User- } \\
\text { oriented } \\
\text { PSS) }\end{array}$ & Yes \\
\hline $\begin{array}{l}\text { Finnish Energy Service COmpanies (ESCOs), Finland } \\
\text { Description of the PSS. In the ESCO model companies offer their customers a broad range } \\
\text { of comprehensive energy solutions (e.g. designs and implementation of energy savings } \\
\text { projects, energy conservation, energy infrastructure outsourcing, etc.). ESCOs gain their } \\
\text { returns by receiving a share of the energy costs saved. If the project does not provide returns } \\
\text { on the investment, the ESCO is often responsible to pay the difference. ESCOs are therefore } \\
\text { economically incentivised in reducing the buildings energy consumption as much as possible. } \\
\text { Brief description of the implementation and diffusion process. The ESCO model has } \\
\text { been publicised in Finland for some years. However the model in } 2000 \text { was not widely } \\
\text { adopted. For this reason, in order to speed up ESCO activities, the Finnish Ministry for Trade } \\
\text { and Industry (MTI) awarded investment subsidies to ESCO projects during } 2001 \text {. In order to } \\
\text { foster the diffusion of ESCO models, a network made up of ESCOs, municipalities, financial } \\
\text { institutions, a governmental institution and a research centre, was established. Working } \\
\text { groups and brainstorming sessions were organized in order to combine and match the needs } \\
\text { and perspective of the different involved stakeholders, and to try to solve the implementation } \\
\text { and diffusion barriers. As result pilot projects in collaboration with municipalities took place, } \\
\text { and policy measures were adopted to favour the ESCO models. After the experimentation the } \\
\text { number of ESCO projects in Finnish municipalities remained modest up to } 2001 \text { but rose } \\
\text { considerably in the following years. }\end{array}$ & $\begin{array}{l}\text { B2G, B2B } \\
\text { (Result- } \\
\text { oriented } \\
\text { PSS) }\end{array}$ & Yes \\
\hline QURRENT, Qurrent, The Netherlands ${ }^{12}$ & $\mathrm{~B} 2 \mathrm{~B}, \mathrm{~B} 2 \mathrm{C}$ & Yes \\
\hline
\end{tabular}

\footnotetext{
${ }^{10}$ Primary sources: semi-structured interview with Vittoria Bono (ideator of the PSS concept) and Valentina Rovetta (EGO sole administrator). Secondary sources: newspaper articles; website (www.suiteatwork.it).

${ }^{11}$ Secondary sources: case study made by Kivisaari et al. (2004); Finnish Ministerial report: Ministry of Trade and Industry (2003), and Ministry of Trade and Industry (2007); website (www.motiva.fi).

12 Secondary sources: case study made by Keskin (2010); website (www.qurrent.com); newspaper articles.
} 


\begin{tabular}{|c|c|c|}
\hline $\begin{array}{l}\text { Description of the PSS. Qurrent enables people to produce and manage renewable energy } \\
\text { by their own. Qurrent develops devices, software and services that enable the creation of } \\
\text { small local energy networks (decentralised renewable energy systems). Within these } \\
\text { networks users exchange energy to maximize the efficiency of the energy they produce. To } \\
\text { do this Qurrent developed three core products: the Qbox (it measures all electricity } \\
\text { production and consumption and makes it possible to share capacities with the } \\
\text { neighbourhood), the Qmunity website (the place where Qurrent members go to analyse their } \\
\text { energy consumption and production), the Qserver (where all measures by all members are } \\
\text { stored); together they constitute the Local Energy Network. } \\
\text { Brief description of the implementation and diffusion process. Igor Kluin (founder of } \\
\text { Qurrent) presented his business idea in } 2006 \text { in an innovation contest, and won } 250,000 € \text {, } \\
\text { which were used to develop the first generation of the Qbox. In } 2007 \text { Qurrent won another } \\
\text { environmental prize, consisting of } 500,000 € \text { plus consulting and accounting help. Thanks to } \\
\text { the prize Qurrent had the opportunity to set up seven pilot projects (currently running) to test } \\
\text { the technical and usability aspects of its system, verify the acceptation by different kind of } \\
\text { actors (private users, public administration, local energy suppliers, etc), and learn about } \\
\text { implementation and diffusion barriers. Since } 2008 \text { Qbox is on the market (available only in } \\
\text { the Netherlands). }\end{array}$ & $\begin{array}{l}\text { and B2G } \\
\text { (User- } \\
\text { oriented } \\
\text { PSS) }\end{array}$ & \\
\hline $\begin{array}{l}\text { ARISTON, PayXUse, Italy } \mathbf{1 3}^{\mathbf{3}} \\
\text { Description of the PSS. PayXUse, developed by the Italian appliances manufacturer Ariston, } \\
\text { is a PSS that provides to clients the access to washing machines (owned by Ariston). Payment } \\
\text { is based on number of washes and includes: delivery of a washing machine at home (not } \\
\text { owned by customers), electricity supply, maintenance, up-grading and end-of-life collection. } \\
\text { Brief description of the implementation and diffusion process. The PSS concept was } \\
\text { developed in 1999, in collaboration with ENEL (an Italian energy supplier). A first field test } \\
\text { took place in 2000. In 2001, after solving the technical problems emerged during the field } \\
\text { test, the PSS was launched in Lombardia and Marche (two Italian regions) in a limited amount } \\
\text { of kits (around 500). At the end of } 2001 \text { the company decided to not launch the PayXUse in } \\
\text { the market. The main reason that brought Ariston to this decision was the fact that the } \\
\text { system was based on internally developed communication technologies and standards (not } \\
\text { shared with the other main producers). Going on was therefore considered a risk because } \\
\text { these standards were not shareable with the other main appliances producers (producers } \\
\text { which at that time were planning to enter the market with a common communication } \\
\text { standard and protocol). }\end{array}$ & $\begin{array}{l}\text { B2C } \\
\text { (User- } \\
\text { oriented } \\
\text { PSS) }\end{array}$ & No \\
\hline $\begin{array}{l}\text { INTERFACE FLOORING SYSTEM, Evergreen Lease, USA } \\
\text { Description of the PSS. As an alternative to a conventional purchase of carpet floors, clients } \\
\text { "lease" the services (functionality, colour, design, aesthetics) of a modular carpet system } \\
\text { without taking ownership or liability for maintenance and disposal of the products. A service } \\
\text { package is offered inclusive of design layouts, product selection (choosing the right products } \\
\text { for the right place), carpet installation, ongoing maintenance and ultimate removal for } \\
\text { recycling. Evergreen was priced cheaper than the bought equivalent over the lifespan of a } \\
\text { carpet. } \\
\text { Brief description of the implementation and diffusion process. The PSS solution was }\end{array}$ & $\begin{array}{l}\text { B2B and } \\
\text { B2C } \\
\text { (Result- } \\
\text { oriented } \\
\text { PSS) }\end{array}$ & No \\
\hline
\end{tabular}

\footnotetext{
${ }^{13}$ Primary sources: questionnaire filled by Valerio Aisa (Indesit scientific advisor, and former project manager of the PayXUse project); interview with Valerio Aisa. Secondary sources: newspaper articles; internal documents provided by Indesit (former known as Ariston).

${ }^{14}$ Secondary sources: case study made by Oliva and Quinn (2003); Case study made by Tischer (2006); presentation made by Joan Reynolds and Graham Scott (Interface Flooring Systems, Inc.) in a workshop on extended product responsibility (1997, USA); website (www.interfaceflor.com).
} 
ideated by Interface Flooring System in the first years of the '90 and marketed in 1995.

Interface signed its first lease agreement in 1995 with the Southern California Gas Company.

Many potential customers emerged enthusiastic for the carpet-leasing idea but unfortunately, despite the sales effort lead by the company, the majority of negotiations broke down. Only six lease agreements have been signed from 1995 to 2003 . The reason of the missed success was mainly related to the financial accounting standards related to lease agreements, which made Evergreen Lease a capital lease instead of an operating lease, which is less favourable for customers. In addition some customers did not perceive the full cost of purchasing and maintaining carpets, which made difficult for them to understand the potential economic advantages of Evergreen Lease.

Table 2. Overview of the cases analysed. For each case a brief description of the PSS innovation and its implementation and diffusion process is provided.

\subsection{Results}

The following text reports the results of the case studies. For each of the four clusters it is discussed if the expected factors have been confirmed or not, and if new factors have emerged from the cases. An overview of the expected and new factors in relation to the six cases is provided by Table 3.

\subsubsection{Socio-technical experiments and societal embedding}

The successful cases analysed in this paper are all characterised by a commercialisation strategy based on the implementation of one or more socio-technical experiments. It has however to be underlined that we are not dealing with simple experiments done inside a company's laboratory and exclusively aimed at improving the technical and/or usability aspects of the innovation, but with experiments undertaken in real settings involving a variety of actors and aimed at learning at many different dimensions (user preferences, political, regulative, cultural, social, etc.). For example in Finland, in order to foster the diffusion of Energy Service COmpanies (ESCOs), a network made up of ESCOs, municipalities, financial institutions, a governmental institution and a research centre was established; pilot projects were implemented in order to not only adapt the ESCO models to the municipalities' needs, but also to learn about the most effective financial and policy measures to support the PSS innovation (Ministry of Trade and Industry 2003; Kivisaari et al. 2004).

Experiments showed to be crucial to incubate and shape new PSS innovations (and the related socio-technical practices, habits and institutions), and also to stimulate and influence relevant actors to support and protect the innovations (and therefore favour their societal embedding). For example the bike sharing system ideated by Clear Channel Outdoor was firstly implemented as a small pilot project in the city of Rennes; the pilot was used to attract the interest of the local public transport company, involve it in discussions and negotiations, 
and finally develop synergies to stimulate public transport users to adopt the bike sharing system (Verrecchia 2009).

Moreover, in successful cases, experiments were also used to stimulate changes in actors' behaviours and habits. Continuing with the previous example, Clear Channel Outdoor states that the pilot was conceived as a way to show a new idea to the community, and stimulate potential users to get in touch with it and reflect about their mobility behaviours and routines (Verrecchia 2009).

In addition, another important element found in successful cases is the use of experiments as a means of communication to raise interest on the innovation project and the related actors. In other words experiments (and this is something that SNM and TM do not explicitly underline) were used as a sort of "windows" to disseminate the innovation results and facilitate the enrolment of new actors (e.g. new users, potential partners etc.). For example: when, in 1998, the bike sharing system in Rennes was improved and scaled up in a full operative service, Clear Channel Outdoor used it to demonstrate to other municipalities the potentialities of the PSS (e.g. municipalities were invited to visit the pilot); this was crucial in facilitating the gradual diffusion of the solution in other cities (Verrecchia 2009).

In synthesis, successful cases are characterised by a strategic use of socio-technical experiments to: learn on many different dimensions (technical, usability, regulative, political, cultural and social acceptance, etc.); influence contextual conditions in order to favour the societal embedding process (stimulate changes in actors' behaviours and practices to protect and support the PSS innovations); communicate the PSS potentialities to attract and enrol new relevant actors. These characteristics cannot be found in the analysed unsuccessful cases, where experiments were mainly used to only verify and improve the technical aspects of the PSS. For example in the PayXUse case, the two pilot projects implemented in 2000 and 2001 were only focused on testing and improving technical issues (e.g. product requirements, data communication system), commercial issues (distribution channels), and usability issues (user interactions) (Aisa 2009).

SNM and TM point out the importance of creating partially protected environments (financial and socio-institutional protections) where innovations can mature without the direct influence of dominant regimes (Schot and Hoogma 1996; Schot and Geels 2008). Successful cases show that financial protection played a significant role in the first phases of experiments (setting up and implementation), while in the subsequent phases protection was gradually removed. On the other hand socio-institutional protection (new social relationships, routines, standards, etc.) was not dismantled, but rather reinforced and transferred into mainstream settings. For example, in the Finnish ESCOs case, the financing provided by the National Technology Agency of Finland (Tekes) was fundamental to set up initial workshops and roundtables, and implement pilot projects (Kivisaari et al. 2004). After the pilot project, institutional protection came from the Finnish Ministry of Trade and Industry, which inserted in its action plan for energy efficiency (2003-2006) recommendations on how to stimulate the 
ESCO models (i.e. new regulations, adoption of green public procurement) (Ministry of Trade and Industry 2003). In addition institutional protection came also from the dissemination activities implemented by the Ministry to make Finnish municipalities aware of the ESCO models (Kivisaari et al. 2004, Ministry of Trade and Industry 2007). However, as showed by the EGO example, successful implementation can take place even without protecting the first phases of the process. In this case PSS promoters tried, unsuccessfully, to get financial and institutional protection from the Italian Fashion Chamber and potential industrial partners; the missing protection resulted in a slowdown of the project development (Bono 2009; Rovetta 2009), but did not compromise its implementation.

SNM and TM theorists argue that the implementation of sequences of experiments (and their repetition in different domains and contexts) is crucial to lead to the development and reinforcement of the niche (Raven 2005; Rotmans and Loorbach 2006). This is not fully confirmed by the successful cases analysed, which are characterised by the implementation of few experiments ( 1 in the EGO and SmartBike cases, and 3 in the ESCOs case). An exception is represented by the Qurrent case, in which 7 pilot projects were implemented to test their solutions in different settings (Qurrent 2009). Of course the implementation of a variety of experiments is important because can increase learning opportunities (e.g. learning about different designs in different contexts). On the other hand this strategy could be hindered by the limited financial resources that companies have for investing in experimental pilot projects (as in the cases of SmartBike and Ego (Verrecchia 2009; Rovetta 2009)).

As underlined by SNM and TM, even if experiments in protected spaces are key important for transitions, scaling-up can take place if there is an alignment with events and developments in the landscape (Geels 2005), and if the regime is sufficiently open to accept radical novelties (Rip and Kemp 1998). Successful cases show this correspondence. For example in the Finnish ESCO case, ESCO models were favoured by growing pressure from climate protection and growing energy prices (landscape development), which led to new energy taxes and stricter building regulations (regime development) (Kivisaari et al. 2004).

\subsubsection{Actor network}

The successful cases analysed in this paper are characterised by the involvement of a broad network, including actors from many different domains (e.g. users, governmental institutions, NGOs, special interest groups, research centres, etc.). A partial exception is represented by the EGO case, which shows a narrower network: in addition to suppliers and industrial partners, actors involved were potential users and (indirectly) environmental NGOs and media (Bono 2009).

More in details, successful cases show networks that combine outsiders and insiders actors (in relation to the regime). For example in the Finnish ESCO case, the network included: innovative companies and scientists from the Technical Research Centre of Finland on one hand (outsiders); municipalities, financial institutions and governmental institutions on the 
other (insiders). As underlined by van den Bosch et al (2008), this combination is important in order to couple the potentialities of outsiders in triggering innovations that deviate from the regime, and the potentialities of insiders in directly influencing regime culture, practices and institutions.

In particular successful cases demonstrate the crucial role that can be played by actors such as governments, governmental agencies, local administrations, etc. in directly creating a favourable environment for the PSS innovation. For example in the Finnish ESCO case, the Ministry of Trade and Industry and two governmental agencies (Tekes and Motiva) were decisive in funding the pilot projects, and also in adjusting regulations to facilitate the ESCO models adoption (Kivisaari et al. 2004).

An important role was also undertaken by actors such as environmental NGOs and societal pressure groups, because they contributed in disseminating the experiments results and mobilising public opinion. For example in the SmartBike case, the "publicity" provided by local NGOs was an important factor that brought to get exposure and attract potentially interested municipalities (Verrecchia 2009). In addition, also media showed to be important in disseminating the PSS innovations. As declared by Rovetta (2009), the first customers of the EGO service decided to try it because they read an article on a newspaper or a specialised magazine.

In synthesis successful cases show that companies adopted a strategic behaviours oriented at influencing the context in which the PSS should be introduced. In particular companies set up project networks trying to include those actors that, directly or indirectly, could have affected the regime (and thus create more favourable conditions for the adoption and further diffusion of the innovation).

The lack of a broad network is an important explanation of the relative failure of the PayXUse and Evergreen Lease cases. For example, in the PayXUse case, the main reason that brought the company to not introduce the solution in the market was the lack of a proper network capable to support the communication standard and protocols on which the solution was based (Aisa 2009). Going on was therefore considered a risk because such standards and protocols were not shared with the other main appliances producers (ibid.). Building up relationships and agreements, with other producers and agencies that develop protocols and standard, could have brought to facilitate the adoption of Ariston's technology as a standard.

\subsubsection{Project vision}

As illustrated in the previous section, the establishment of a broad network of actors is crucial in order to facilitate the societal embedding process of PSS innovations. In relation to this, SNM and TM point out that the development of proper project visions is fundamental in order to attract and enrol actors and give a strategic direction to the innovation (Kemp and Rotmans 2004; Kemp and Loorbach 2006; Raven 2005). Therefore it is key important for companies to be able to formulate clear visions (to make explicit their expectations), and be 
able to communicate those visions in an effective way. For example in the Qurrent case, the ability of the company founder in presenting the project vision (underlining all the potential economic and environmental benefits) was fundamental because it allowed to get the first funds (the Qurrent project idea was awarded in two important innovation contests), and because it facilitated the involvement of a variety of actors for the pilot projects implementation. The vision was structured in such a way in order to clearly illustrate how the solution would have worked and what (economic, environmental, etc.) advantages the implementation would have brought to the different stakeholders and the community. It resulted crucial for convincing funding bodies to invest on the idea, and for achieving a shared consensus (among the actors involved in the pilot projects) about the strategic direction to be followed.

It has however to be underlined that in successful cases the project vision was not kept fixed, but rather open to adjustments. For example in the SmartBike case, the initial project vision was modified once the public transport company in Rennes got involved in the project: the PSS solution was in fact refined in order to favour synergies between public transports and the use of SmartBike (Verrecchia 2009). It is also important to not try to force consensus on a vision, but try to make explicit the different actors' expectations, and use these expectations as a basis for discussions and negotiations (Jolivet et al. 2003). This is exactly what was done in the Finnish ESCO case: before implementing the pilot projects, a six months incubation phase was set up in order to organise discussions, seminars and workshops (involving all the actors) with the aim to develop a shared ESCO model (Kivisaari et al. 2004).

The difficulties faced by the EGO in formulating and communicating its project vision in an effective way is an important explanation of the failure in establishing financial and industrial relations with other actors. As stated by Bono (2009), the Italian Chamber of Fashion, the financial institutions and the potential industrial partners contacted by the company, did not believe in the economic and environmental potential of the PSS innovation, and for this reason they decided to do not support the project.

\subsubsection{Learning processes}

The analysed cases show that learning processes are strictly related to how experiments are designed and managed. The experiments that focused not only at exploring and testing the technical aspects, but also the ones related to usability, policy, regulations, social acceptance etc., easily brought to broad learning processes. For example in the SmartBike case, the pilot project brought to learn on technology (e.g. the docking station to lock and unlock bikes), user preferences (e.g. the service interactions to register and use bikes), regulations (e.g. how local administrations can support the solution), social acceptance (e.g. how to communicate the solution environmental benefits), strategic partnerships (e.g. how to build mutual synergies with the local public transport company) (Verrecchia 2009). 
Successful cases not only show broad learning processes, but also reflexive ones. Reflexive learning is fundamental in order to break down actors' accepted assumptions and routine behaviours (Kemp and van den Bosh 2006), and induce changes in culture, practices and institutions (Van den bosh 2008; Brown et al. 2003; Brown and Vergragt 2008). For example in the SmartBike case, the first experiment implemented in Rennes induced reflexive learning in potential users (the novelty introduced by the pilot stimulated them to get in touch with the innovation and to potentially rethink about their mobility behaviours and routines), and in the local administration and public transport company (the pilot induced them to think about new alternative ways to plan mobility in city centres). As suggested by many authors, interactions among a heterogeneous set of actors (with different expectations, belief systems and interpretative frames) is a stimulus for reflexive learning (Hoogma and Schot 2001; Lynn et al. 1996; Brown and Vergragt 2008). This correlation between network heterogeneity and reflexive learning is confirmed in successful cases.

Another important issue is related to creating diversity among experiments, which is considered crucial because can led to learning about different designs in different use environments (Kemp and Loorbach 2003; Raven 2005; Van der Laak et al. 2007). This diversity can be found only in the Finnish ESCOs and Qurrent cases, were a variety of pilot projects were simultaneously implemented to learn about different contexts. For example in the Qurrent case, their decentralised renewable energy system was implemented in different settings: private families, housing corporations and office buildings (Qurrent 2009); this stimulated learning about different designs in different use environments. It has however to be underlined that the number of experiments and their degree of diversity depend on the available economic resources, and even if variety is considered important (e.g. to learn in different market contexts (Lynn et al. 1996)), companies could sometimes be financially limited in applying this strategy (as in the EGO case).

\begin{tabular}{|c|c|c|c|c|c|c|c|c|c|}
\hline & & Expected and new factors & 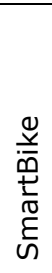 & 苛 & 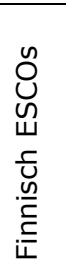 & $\begin{array}{l}\stackrel{+}{\frac{\pi}{2}} \\
\frac{2}{2} \\
\frac{2}{2}\end{array}$ & 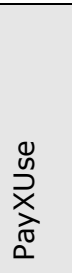 & 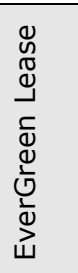 & \\
\hline \multirow{6}{*}{ 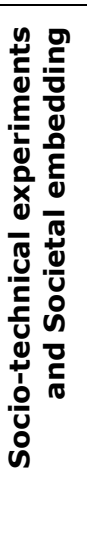 } & EF1 & $\begin{array}{l}\text { One or more socio-technical experiments are } \\
\text { implemented }\end{array}$ & + & + & + & + & + & - & + \\
\hline & EF2 & $\begin{array}{l}\text { Socio-technical experiments contribute to learn on } \\
\text { many different dimensions (e.g. technical, user } \\
\text { acceptance, political, regulative, cultural and social } \\
\text { acceptance, etc.) }\end{array}$ & + & $+/-$ & + & + & - & $N A^{I}$ & + \\
\hline & EF3 & $\begin{array}{l}\text { Socio-technical experiments contribute to influence the } \\
\text { socio-technical context in order to stimulate the } \\
\text { societal embedding of the PSS innovation }\end{array}$ & + & $+/-$ & + & + & - & $N A^{I}$ & + \\
\hline & EF4 & $\begin{array}{l}\text { Socio-technical experiments are initially implemented } \\
\text { in an environment protected from the mainstream } \\
\text { market selection (financial protection) }\end{array}$ & + & - & + & + & - & $N A^{I}$ & + \\
\hline & EF5 & $\begin{array}{l}\text { Niche development is supported by repeating the } \\
\text { experiment in a variety of contexts, and linking the } \\
\text { experiment/s to other functions or domains }\end{array}$ & - & - & $+/-$ & + & - & $N A^{I}$ & $+/-$ \\
\hline & EF6 & Financial protection of socio-technical experiments is & + & - & + & + & $\mathrm{NA}^{\mathrm{II}}$ & $N A^{I}$ & + \\
\hline
\end{tabular}




\begin{tabular}{|c|c|c|c|c|c|c|c|c|c|}
\hline & & $\begin{array}{l}\text { gradually dismantled during the niche development } \\
\text { process, while institutional protection is reinforced and } \\
\text { transferred into mainstream settings }\end{array}$ & & & & & & & \\
\hline & EF7 & $\begin{array}{l}\text { Niche development and scaling-up are favoured if } \\
\text { there is an alignment of the niche with events and } \\
\text { developments in the landscape }\end{array}$ & + & + & + & + & $\mathrm{NA}^{\mathrm{II}}$ & $\mathrm{NA}^{\mathrm{III}}$ & + \\
\hline & $N F 1$ & $\begin{array}{l}\text { Socio-technical experiments are used as "windows" to } \\
\text { disseminate and communicate the innovation results }\end{array}$ & + & + & + & + & - & $N A^{I}$ & \\
\hline \multirow{7}{*}{ 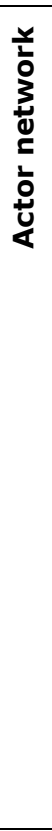 } & EF8 & $\begin{array}{l}\text { The stakeholder network is broad (partners, suppliers, } \\
\text { users, but also policy makers, governmental agencies, } \\
\text { NGOs, research centres, media etc.) }\end{array}$ & + & $+/-$ & + & + & - & - & + \\
\hline & EF9 & $\begin{array}{l}\text { The stakeholder network includes both insiders and } \\
\text { outsider actors (with respect to the dominant regime) }\end{array}$ & + & - & + & + & - & - & + \\
\hline & EF10 & $\begin{array}{l}\text { Support and protection from governmental and public } \\
\text { institutions could provide legitimacy and stability to the } \\
\text { project }\end{array}$ & + & $N A^{I V}$ & + & + & $\mathrm{NA}^{\mathrm{IV}}$ & $\mathrm{NA}^{\mathrm{IV}}$ & + \\
\hline & EF11 & $\begin{array}{l}\text { The involvement of actors that have the power and } \\
\text { willingness to directly influence the dominant culture, } \\
\text { practices and structure (such as Ministries, agencies } \\
\text { that develop protocols and standards, policy makers, } \\
\text { politicians, directors, etc.) contributes to niche } \\
\text { development and scaling-up }\end{array}$ & + & $N A^{V}$ & + & + & $\mathrm{NA}^{\mathrm{V}}$ & $N A^{V}$ & + \\
\hline & EF12 & $\begin{array}{l}\text { The involvement of actors that indirectly influence the } \\
\text { regime because they have an interest in embedding } \\
\text { sustainable practices in society (such as NGOs, } \\
\text { sustainability ambassadors, frontrunners in a sector or } \\
\text { policy domain, etc.) contributes to niche development } \\
\text { and scaling-up }\end{array}$ & + & + & + & + & $\mathrm{NA}^{\mathrm{VI}}$ & $\mathrm{NA}^{\mathrm{VI}}$ & + \\
\hline & EF13 & The network composition is kept open to adjustment & + & $\mathrm{NA}^{\mathrm{VII}}$ & + & + & $\mathrm{NA}^{\mathrm{VII}}$ & NA $A^{\mathrm{VII}}$ & + \\
\hline & NF2 & $\begin{array}{l}\text { The stakeholder network is supported by actors that } \\
\text { can mobilise public opinion (in particular media and } \\
\text { NGOs) }\end{array}$ & + & + & - & + & - & - & \\
\hline \multirow{4}{*}{$\begin{array}{l}\frac{5}{0} \\
\frac{2}{2} \\
\frac{n}{2} \\
\frac{0}{2} \\
\frac{0}{2}\end{array}$} & EF14 & $\begin{array}{l}\text { Actors expectations are aligned on a shared project } \\
\text { vision }\end{array}$ & + & $\mathrm{NA}^{\mathrm{VIII}}$ & + & + & + & $\mathrm{NA}^{\mathrm{IX}}$ & + \\
\hline & EF15 & $\begin{array}{l}\text { The involvement of different actors in the development } \\
\text { of the project vision (participatory approach) can } \\
\text { contribute to build-up a shared vision }\end{array}$ & + & $N A^{I X}$ & + & + & + & $N A^{I X}$ & + \\
\hline & EF16 & $\begin{array}{l}\text { The development of a clear and robust project vision } \\
\text { contributes to attract resources as well as new actors }\end{array}$ & + & $N A^{x}$ & + & + & $N A^{X I}$ & $N A^{X I}$ & + \\
\hline & EF17 & The project vision is kept open to adjustments & + & + & + & + & + & + & + \\
\hline \multirow{3}{*}{ 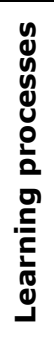 } & EF18 & $\begin{array}{l}\text { Learning is broad: learning about the different } \\
\text { dimensions of the innovation (e.g. institutional, } \\
\text { technological, socio-cultural, environmental, } \\
\text { economical) }\end{array}$ & + & $+/-$ & + & + & - & - & + \\
\hline & EF19 & $\begin{array}{l}\text { Learning is reflexive: there is attention for questioning } \\
\text { underlying assumptions such as social values, and the } \\
\text { willingness to change course if the innovation does not } \\
\text { match these assumptions }\end{array}$ & + & + & + & + & - & - & + \\
\hline & EF20 & $\begin{array}{l}\text { Reflexive learning is facilitated by the involvement of } \\
\text { an heterogeneous set of different actors in the network }\end{array}$ & + & + & + & + & $N A^{X I I}$ & $N A^{X I I}$ & + \\
\hline
\end{tabular}

Table 3. List of the expected (and new) factors, which can influence the process of societal embedding of eco-efficient PSS innovations, against the six cases analysed (Legend: "EFn": expected factor; "NFn": new factor; "+": confirmed; "+/-": partly confirmed; "-": not confirmed; "NA": not applicable. Notes: light grey columns indicate unsuccessful cases; dark grey column provides an overall evaluation of expected factors). See Appendix I for additional notes. 


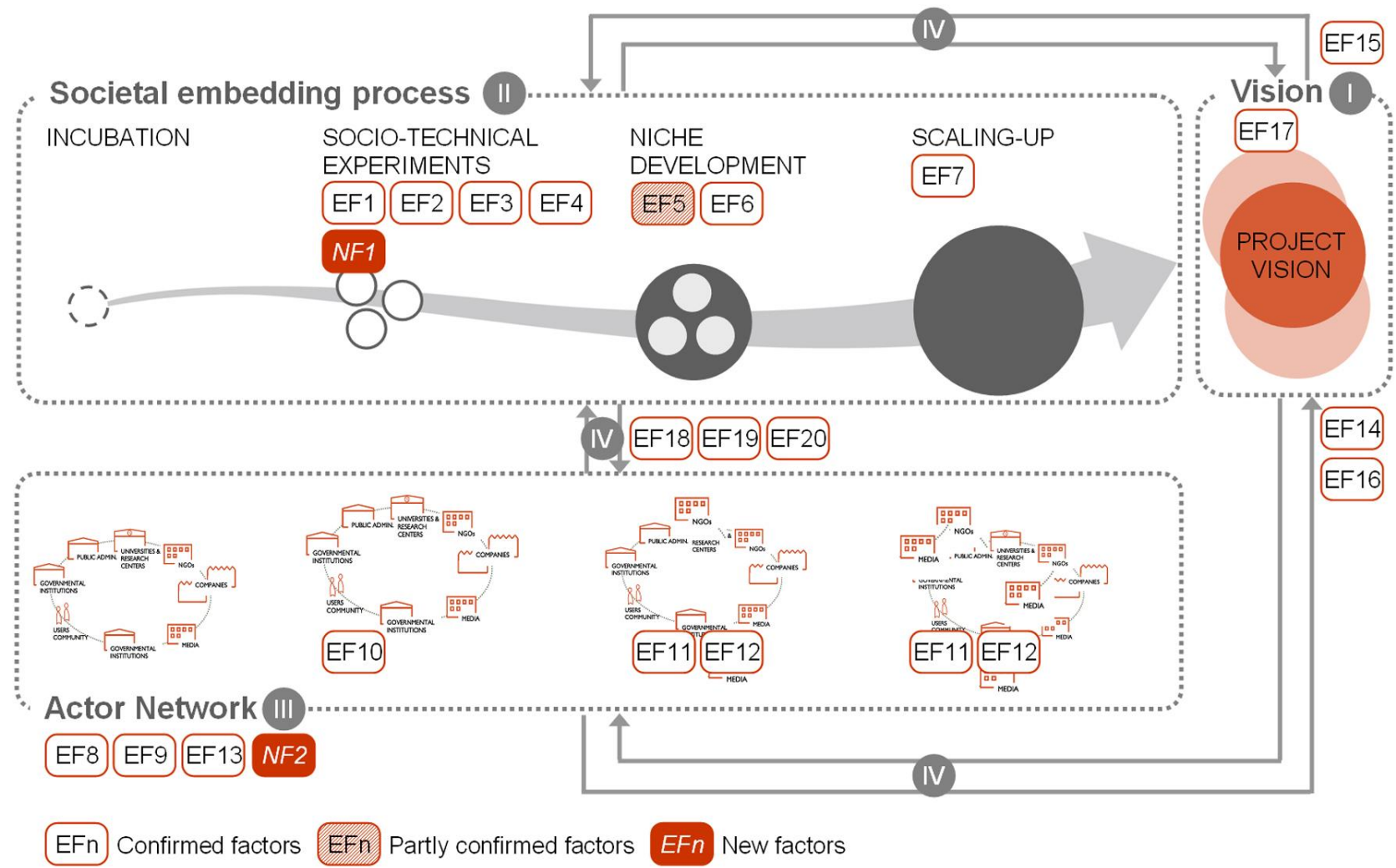

Fig. 2. Refined conceptual framework for the implementation and diffusion of eco-efficient PSSs. Numbers indicate the expected factors that can influence the process (see Table 3).

\section{Conclusions}

Building upon innovation studies (and in particular upon SNM and TM), this paper has put forward a conceptual framework that provides a structured overview of the factors considered important to favour the societal embedding of eco-efficient PSS innovations. A case studies analysis was used to validate and refine the framework: almost all the expected factors derived from the literature review were encountered in successful cases, one was partly confirmed (EF5), and two new factors emerged from the cases were added (NF1 and NF2). Results are illustrated in table 3 and figure 2. Factors can be grouped in four main clusters:

- socio-technical experiments and societal embedding process: factors related to the implementation of experiments (financially and/or institutionally protected) in real settings, aimed at testing and improving the innovation, learning on many different dimensions (technical, usability, regulative, political etc.), and exploring how to influence contextual conditions to stimulate and promote its societal embedding;

- actor network: factors related to the building up of a broad network including a variety of actors (partners, suppliers, users, but also policy makers, governmental agencies, NGOs, research centres, media etc.), in order to support and protect the innovation, and also to (directly and/or indirectly) influence dominant practices and institutions; 
- project visions: factors related to the formulation of a clear project vision capable to converge actors' expectations and provide strategic direction to the innovation development; and a flexible vision open to adjustments (in relation to what is learned by actors);

- learning processes: factors related to the creation of room for broad learning (learning about the PSS innovation and also about the different dimensions of context in which the innovation should be introduced), and reflexive learning (learning resulting in changes in actors' reference framework, beliefs, behaviours, practices etc.).

It is important to underline that these factors are strictly interrelated. Socio-technical experiments (as they have been described in this paper) require in fact the involvement of a broad network of actors. In order to involve actors, as well as to align their expectations, project visions are fundamental. The implementation of experiments stimulates learning processes, and what is learned by actors is continuously used to adjust the project vision, the network composition and the socio-technical experiments. Sequences of learning processes and experiment adjustments can allow the innovation to mature, and can give body to more stable socio-technical practices and institutions (capable to potentially influence the dominant regime).

It has to be emphasised that the list of factors provided by this paper should be seen as general management indications, and not as a "recipe for success". Niche development and scaling up require in fact favourable conditions and circumstances (e.g. there should be enough pressure form the landscape, the regime should be sufficiently open to accept radical innovations, etc (Rip and Kemp 1998)). These conditions and circumstances may be not directly (or indirectly) influenced by companies. Therefore the process from incubation to scaling-up becomes increasingly more uncertain and less manageable, and more influenced by project-external events and dynamics. However the successful cases presented in this paper show that the adoption of an experimental-, learning-, and network-based management approach, can increase chances of success (speed up and increase the possibilities to set up a market niche in which the innovation is commercialised).

An important conclusion of this paper is that a different management attitude is required by companies:

- first, a much broader system approach is needed. Companies should focus not only on the PSS solution and its value chain, but also on the contextual conditions that may favour or hinder the societal embedding of the PSS itself. This means that companies should adopt a strategic attitude oriented to influence the socio-technical context, in order to create the most favourable conditions for the innovation (i.e. by involving those actors that, directly or indirectly, could affected regime practices and institutions). 
- second, a "multi-term" strategic attitude is needed. The formulation of a project vision (the long term goal to be achieved) should be combined with the strategic identification of the short and medium term actions to be undertaken in order to orient the innovation development towards the achievement of the vision (visioning and backcasting exercise (Quist et al. 2006; Van den Bosch et al. 2005)).

- third, a flexible and dynamic approach should be adopted. In fact, the project vision is not a static outcome to be achieved, and the transition strategy is not a fixed roadmap to be covered. What is learned by actors during the societal embedding process is used to adjust the project vision and, as a consequence, to re-orient the societal embedding strategy and refine the network composition.

Eco-efficient PSSs, if properly conceived, represent promising business models to potentially combine economic value with sustainability. On the other hand significant challenges (corporate, user and regulatory barriers) have to be faced by those companies that do want to implement this kind of solutions. In relation to this, SNM and TM have proved to be insightful, and a set of important factors (that can influence the societal embedding process) have been drawn from these approaches and adapted to the specificities of PSS innovations.

On the basis of these results, a relevant research direction is to understand how to translate these factors and indications into an instrumental step-by-step approach (and related tools, guidelines etc.), to be used by companies, project managers and management consultants to design, manage and orient the process of introduction and diffusion of this kind of innovations.

\section{Acknowledgements}

The author would like to thank three anonymous referees for their useful comments and suggestions on the first version of this paper.

\section{Appendix I: additional notes to Table 3}

I. Since in the Evergreen Lease case no experiment was implemented, this expected factor cannot be taken into consideration.

II. Since the PayXUse PSS was never scaled up, this expected factor cannot be taken into consideration.

III. Since the Evergreen Lease PSS was never scaled up, this expected factor cannot be taken into consideration.

IV. Since in the EGO, PayXUse and Evergreen Lease cases there was not any support and protection from governmental and public institutions, this expected factor cannot be taken into consideration. 
V. Since in the EGO, PayXUse and Evergreen Lease cases there was not any involvement of actors capable to directly influence the dominant regime, this expected factor cannot be taken into consideration.

VI. Since in the PayXUse and Evergreen Lease cases there was not any involvement of actors capable to indirectly influence the dominant regime, this expected factor cannot be taken into consideration.

VII. Since in the EGO, PayXUse and Evergreen Lease cases the network composition did not change along the innovation journey, this expected factor cannot be taken into consideration.

VIII. In the EGO case the vision was developed entirely inside the company without involving any other relevant actor. Thus, this expected factor cannot be taken into consideration.

IX. In the Evergreen Lease case the innovation journey was undertaken entirely by the company without involving any other relevant actor. Thus, this expected factor cannot be taken into consideration.

X. The project vision in the EGO case cannot be considered clear and robust. Thus, this expected factor cannot be taken into consideration.

XI. Since in the PayXUse and Evergreen Lease cases the vision was not used to attract actors and/or resources, this expected factor cannot be taken into consideration.

XII. Since in the PayXUse and Evergreen Lease cases the network composition was not heterogeneous, this expected factor cannot be taken into consideration.

\section{References}

Akrich, M., 1992. The Description of Technological Objects, in: Bijker, W., Law, J. (Eds.), Shaping Technology/Building Society Studies in Socio-Technical Change. MIT Press, Cambridge.

Aisa V. (personal communication, November 20, 2009)

Baines, T., Lightfoot, H., Evans, S., Neely, A., Greenough, R., Peppard, J., Roy, R., Shehab, E., Braganza, A., Tiwari, A., Alcock, J., Angus, J., Bastl, M., Cousens, A., Irving, P., Johnson, M., Kingston, J., Lockett, H., Martinez, V., Micheli, P., Tranfield, D., Walton, I., Wilson, H., 2007. State-of-the-art in Product Service-Systems. Proceedings of the Institution of Mechanical Engineers, Part B: Journal of Engineering Manufacture, 221(10): 1543-1552.

Behrendt, S., Jasch, C., Kortman, J., Hrauda, G., Pfitzner, R., Velte, D., 2003. Eco-Service Development: Reinventing Supply and Demand in the European Union. Greenleaf Publishing, Sheffield.

Berkhout, F., 2006. Normative expectations in systems innovation. Technology Analysis \& Strategic Management, 18(3): 299-311.

Bono V. (personal communication, November 18, 2009). 
Brezet H., Bijma, A.S., Ehrenfeld, J., Silvester, S., 2001. The design of eco-efficent services. Methods, tools and review of the case study based "Designing eco-efficent Services" project. Report for Dutch Ministries of Environment (VROM).

Brown, H.S., Vergragt, P.J., Green, K., Berchicci, L., 2003. Learning for Sustainability Transition Through Bounded Socio-Technical Experiments in Personal Mobility. Technology Analysis \& Strategic Management, 13(3): 298-315.

Brown, H.S, Vergragt, P.J., 2008. Bounded socio-technical experiments as agents of systemic change: The case of a zero-energy residential building. Technological Forecasting \& Social Change, 75, 107-130.

Ceschin, F., Vezzoli, C., 2010. The Role of Public Policy in Stimulating Radical Environmental Impact Reduction in the Automotive Sector: The Need to Focus on ProductService System Innovation. Int. J. Automotive Technology and Management, 10(2/3): 321341.

Cook, M., Bhamra, T., Lemon, M., 2006. The Transfer and Application of Product ServiceSystems: from Academia to UK Manufacturing Firms, Journal of Cleaner Production, 14(17): 1455-1465.

De Laat, B., 1996. Script for the Future: Technology Foresight, Strategic Analysis and Socio-Technical Networks: the Confrontation of Script Based Scenarios. PhD Thesis, University of Amsterdam.

Elzen, B., Hoogma, R., Schot, J., 1996. Mobiliteit met Toekomst. Naar een Vraaggericht Technologiebeleid. Report for the Dutch Ministry of Tra\$c and Transport, The Hague.

Factor $10 \mathrm{Club}$, 1994. Declaration of the Factor 10 Club, available at http://www.techfak.unibielefeld.de/techfak/persons/walter/f10/declaration94.html.

Geels, F.W., 2002. Technological Transitions as Evolutionary Reconfiguration Processes: a Multilevel Perspective and a Case-Study. Research Policy, 31(8/9): 1257-1274.

Geels, F.W., 2005. Technological transitions and system innovations: a co-evolutionary and socio-technical analysis. Cheltenham: Edward Elgar.

Geels, F.W., Kemp, R., 2000. Transities vanuit sociotechnisch perspectief: achtergrondrapport voor het vierde nationaal milieubeleidsplan (NMP-4), Twente University and Merit, Twente and Maastricht.

Geels, F.W., Raven, R.P.J.M., 2006. Non-Linearity and Expectations in Niche-Development Trajectories. Ups and Downs in Biogas Plant Development (1973-2003). Technology Analysis \& Strategic Management, 18(3/4): 375-392.

Goedkoop, M., van Halen, C., te Riele, H., Rommes, P., 1999. Product Services Systems, Ecological and Economic Basics, report 1999/36. VROM, The Hague.

Hall, P., 1993. Policy Paradigms, Social Learning and the State. The Case of Economic Policymaking in Britain. Comp. Polit., 25(3): 275-96.

Halme M, Jasch C, Scharp M., 2004. Sustainable homeservices? Toward household services that enhance ecological, social and economic sustainability. Ecological Economics, 51(1-2): 125-138.

Hoogma, R., 2000. Exploiting Technological Niches: Strategies for Experimental Introduction of Electric Vehicles, Ph.D. Thesis. Enschede, NL: Twente University Press. 
Hoogma, R., Kemp, R., Schot, J., Truffer, B., 2002. Experimenting for Sustainable Transport: The approach of Strategic Niche Management. Spon Press, London/New York.

Hoogma, R., Schot, J.W., 2001. How innovative are users? A critique of learning-by-doing and-using, in: Coombs, R., Green, K., Richards, A., Walsh, V. (eds.), Technology and the Market, Edward Elgar, Cheltenham/Massachusetts, p. 216-233.

James, P., Hopkinson, P., 2002. Service innovation for sustainability. A new option for UK environmental policy? Bradford University, Bradford.

Jolivet, E., Laredo, P., Shove, E., 2003. Managing breakthrough innovations: theoratical implications from-and for-the sociology of science and technology. Presentation for the 2003 ASEAT Conference Knowledge and Economic \& Social Change: New Challanges to Innovation Studies, Manchester, April 7-9.

Kemp, R., Loorbach, D., 2003. Governance for sustainability through transition management, paper presented at the international IHDP conference, Montreal, Canada.

Kemp, R. \& Loorbach, D. 2006. Transition management: a reflexive governance approach. In J. Voss, R. Kemp, \& D. Bauknecht (Eds.), Reflexive Governance for Sustainable Development. pp. 103-130. Northhampton, MA: Edward Elgar.

Kemp, R., Rip, A., Schot, J., 2001. Constructing Transition Paths Through the Management of Niches, in: Garud, R., Karnøe, P. (Eds.), Path Dependence and Creation. Lawrence Erlbaum, London.

Kemp, R., Rotmans, J., 2004. Managing the Transition to Sustainable Mobility, in: Elzen, B., Geels, W., Green, K. (Eds.), System Innovation and the Transition to Sustainability. Theory, Evidence and Policy. Edward Elgar Publishing, Cheltenham (UK), Northampton (USA).

Kemp, R., Schot, J., Hoogma, R., 1998. Regime Shifts to Sustainability Through Processes of Niche Formation: the Approach of Strategic Niche Management. Technology Analysis \& Strategic Management, 10(2): 175-195.

Kemp, R., van den Bosch, S., 2006. Transitie-experimenten. Praktijkexperimenten met de potentie om bij te dragen aan transities, Delft, The Netherlands: Knowledge Centre for Sustainable System Innovations and Transitions (KCT).

Kivisaari, S., Lovio, R., Vayrynen, E., 2004. Managing experiments for transition: examples of societal embedding in energy and health care sectors, in: Elzen, B., Geels, W., Green, K. (Eds.) System Innovation and the Transition to Sustainability. Theory, Evidence and Policy, Edward Elgar Publishing, Cheltenham (UK), Northampton (USA).

Leonard, D., 1998. Chapter 7: learning from the market, in: Leonard, D., Wellsprings of Knowledge, Harvard Business School Press, Boston/Masachusetts: 177-212.

Loorbach, D., 2002. Transition management: governance for sustainability, paper presented at the international conference on Governance and sustainability, Berlin.

Loorbach, D., 2007. Transition management: new mode of governance for sustainable development. Ph D Thesis. Erasmus University Rotterdam, International Books, Utrecht.

Loorbach, D., Rotmans, J., 2006. Managing transitions for sustainable development. In Oslthoorn, X. and Wieczorek, A., (eds.) Understanding Industrial Transformation: views from different disciplines. Springer Netherlands: 187-206.

Lynn, G.S., Morone, J.G., Paulson, A.S., 1996. Marketing and Discontinuous Innovation: the Probe and Learn Process. California Management Review, 38, 8-37. 
Manzini, E., Collina, L., Evans, S. (Eds.), 2004. Solution oriented partnership. Cranfield University, Cranfield.

Manzini, E., Vezzoli, C., Clark, G., 2001. Product service systems: using an existing concept as a new approach to sustainability. Journal of Design Research, 1(2).

Manzini, E., Vezzoli, C., 2003. A strategic design approach to develop sustainable product service systems: Examples taken from the 'environmentally friendly innovation' Italian prize. Journal of Cleaner Production, 11(8): 851-857.

Marzec, M., 2007. Telling the corporate story: Vision into action. Journal of Business Strategy, 28(1): 26-36.

Ministry of Trade and Industry, 2003. Action plan for energy efficiency 2003-2006. Ad hoc committee reports 4 .

Ministry of Trade and Industry, Ministry of Transport and Communications, Ministry of agriculture and Forestry, Ministry of Finance, Ministry of the Environment, 2007. Finland's National Energy Efficiency Action Plan (NEEAP 2008-2010).

Mont, O., 2002. Clarifying the concept of product-service system. Journal of Cleaner Production, 10(3): 237-245.

Mont, O., 2004. Product-service systems: panacea or myth? Doctoral dissertation, IIIEE Lund University.

Mont, O., Lindhqvist, T., 2003. The Role of Public Policy in Advancement of Product Service Systems. Journal of Cleaner Production, 11(8): 905-914.

Oliva, R., Quinn, J., 2003. Interface's Evergreen Services Agreement. Harvard Business School N9-603-112, 12 February.

Qurrent, 2009. www.qurrent.com/eng/projects.html [accessed 29/08/2010].

Quist, J., Rammelt, C., Overschie, M., de Werk, G. 2006. Backcasting for Sustainability in Engineering Education: the case of Delft University of Technology. Journal of Cleaner Production, 14(9-11): 868-876.

Raven, R.P.J.M., 2005. Strategic Niche Management for Biomass, Eindhoven University of Technology.

Raven, R.P.J.M., Heiskanen, E., Lovio, R., Hodson, M., Brohmann, B., 2008. The contribution of local experiments and negotiation processes to field-level learning in emerging (niche) technologies. Bulletin of Science, Technology and Society, 28(6): 464-477.

Raven, R.P.J.M., van den Bosch, S., Waterings, R., 2010.Transition and strategic niche management: towards a competence kit for practioners. International Journal of Technology Management 51(1), 57-74.

Rip, A., and Kemp, R. 1998. Technological Change. In: Rayner, S., and Malone, E.L. (eds.) Human Choice and Climate Change, Vol. 2, Columbus: Batelle Press, pp. 327-399.

Rotmans, J., 2003. Transitiemanagement: sleutel voor een duurzame samenleving. Koninklijke Van Gorcum, Assen, Nederland.

Rotmans, J. Loorbach, D., 2006. Transition management: reflexive steering of societal complexity through searching, learning and experimenting, in: van den Bergh, J.C.J.M., 
Bruinsma, F.R. (eds.) The transition to Renewable Energy: Theory and Practice. Edward Elger: Cheltenham.

Rovetta V. (personal communication, November 18, 2009).

Schmidt-Bleek, F., 1996. MIPS Book or the Fossil Makers - Factor 10 and More, Berlin, Boston, Basel.

Schot, J., Geels, F.W., 2008. Strategic niche management and sustainable innovation journeys: theory, findings, research agenda, and policy. Technology Analysis \& Strategic Management, 20(5): 537-554.

Schot, J.A., Hoogma, R., 1996. De Invoering van Duurzame Technologies: Strategisch Niche Management als Beleidsinstrument, Programma DTO, Delft: Delft University of Technology.

Stahel, W.R., 1986. Hidden Innovation: R\&D in a Sustainable Society. Science and Public Policy, 13(4): 196-203.

Stahel, W.R., 1989. The Limits to Certainty: Facing Risks in the New Service Economy. Kluwer Academic Publishers, Dordrecht.

Stahel, W.R., 1997. The Functional Economy: Cultural and Organizational Change, in: Richards (Eds.), The Industrial Green Game, National Academy Press: Washington DC.

Stoughton, M., Shapiro, K., Feng, L., Reiskin, E. 1998. The business case for EPR: a feasibility study for developing a decision-support tool. Tellus Institute, Boston (MA).

Tischner, U., 2006. PSS: Carpet Lease, Interface Inc., preparatory case study for Tischner, U. and Vezzoli C., 2010. Product-Service Systems; tools and cases. In: Crul M., Diehl J.C. (Eds.), Design for Sustainability (D4S): A Step-By-Step Approach. Modules, United Nations Environment Program (UNEP), Paris.

Tukker, A., Tischner, U., (eds.), 2006a. New business for Old Europe. Product Services, Sustainability and Competitiveness. Greenleaf publishers, Sheffield.

Tukker, A., Tischner, U., 2006b. A practical guide for PSS development, in: Tukker, A., Tischner, U., (eds.), New business for Old Europe. Product Services, Sustainability and Competitiveness. Greenleaf publishers, Sheffield.

Tukker, A., Tischner, U., 2006c. Product-Services as a Research Field: Past, Present and Future. Reflections from a Decade of Research. Journal of Cleaner Production, 14(17): 15521556.

Tukker, A., van Halen, C., 2003. Innovation scan product service combination: manual. TNO-STB, Delft.

United Nations Environmental Programme (UNEP), 2002. Product-Service Systems and Sustainability. Opportunities for sustainable solutions. UNEP, Division of Technology Industry and Economics, Production and Consumption Branch, Paris.

Van den Bosch, S.J.M., Brezet, J.C., Vergragt, Ph.J., 2005. How to Kick Off System Innovation: a Rotterdam Case Study of the Transition to a Fuel Cell Transport System. Journal of Cleaner Production, 13(10-11): 1027-1035.

Van den Bosch, S. \& Rotmans, J., 2008. Deepening, Broadening, and Scaling up: towards a Conceptual Framework for Transition Experiments, KCT Report. 
Van de Kerkhof, M., Wieczorek, A., 2005. Learning and Stakeholder Participation in Transition Processes Towards Sustainability: Methodological Considerations. Technological Forecasting \& Social Change, 72: 733-747.

Van der Laak, W.W.M., Raven, R.P.J.M., Verbong, G.P.J., 2007. Strategic niche management for biofuels: Analysing past experiments for developing new biofuel policies. Energy Policy, 35: 3213-3225.

Van de Poel, I., 2000. On the role of outsiders in technical development. Technology Analysis and Strategic Management, 12(3): 383-397.

Van Halen, C., Vezzoli, C., Wimmer, R. (eds.), 2005. Methodology for Product Service System. How to develop clean, clever and competitive strategies in companies. Van Gorcum, Assen.

Van Lente, H., 1993. Chapter 6: construction by expectations, in: Lente, H. van, Promising Technology - The dynamics of Expectations in Technological Developments, Twente University: 177-204.

Vergragt, P.J., van Grootveld, G., 1994. Sustainable technology Development in the Netherlands. The first phase of the Dutch STD program. J. of Cleaner Production, 2(3/4): 133139.

Verrecchia S. (personal communication, November 19, 2009)

Vezzoli, C., 2007. System design for sustainability. Theory, methods and tools for a sustainable "satisfaction-system" design. Maggioli Editore, Rimini.

Vezzoli, C., 2010. System design for sustainability. Theory, methods and tools for a sustainable "satisfaction-system" design. $2^{\text {nd }}$ ed. Maggioli Editore, Rimini.

Vezzoli, C., Ceschin, F., Cortesi, S., 2009. Metodi e strumenti per il life cycle design. Come progettare prodotti a basso impatto ambientale. Maggioli Editore, Rimini.

Weber, M., Hoogma, R., Lane, B., Schot, J., 1999. Experimenting with Sustainable

Transport Innovations: A Workbook for Strategic Niche Management. Universiteit Twente, Seville/Enschede.

White, A.L., Stoughton, M., Feng, L., 1999. Servicizing: The Quiet Transition to Extended Product Responsibility. Tellus Institute, Boston.

Williams, A., 2007. Product service systems in the automobile industry: contribution to system innovation? Journal of Cleaner Production 15(11-12): 1093-1103.

Witkamp, M.J., Raven, R.P.J.M., Royakkers, L.M.M., 2011. Strategic Niche Management of Social Innovation: the Case of Social Entrepreneurship. Technology Analysis \& Strategic Management 23(6): 667-681.

World Business Council for Sustainable Development (WBCSD), 1996. Eco-efficient leadership, Final report of the Working Group on eco-efficiency. World Business Council for Sustainable Development, Geneva.

Yin, R.K., 1989. Case study research: Design and methods (Applied Social Research Methods Series, 5). Thousand Oaks, CA: Sage.

Yin, R.K., 1994. Case study research: Design and methods (Applied Social Research Methods Series, 5, 2nd ed.). Thousand Oaks, CA: Sage. 
Yin, R. K., 1998. The Abridged Version of Case Study Research, chapter 8, pages 229-259. In Bickman, L., Rog, D.J. Handbook of Applied Social Research Methods. Sage Publications, Thousand Oaks, CA. 